\title{
Enhanced dissemination of medical student research through the DMJ
}

T his issue of the DMJ outlines the eclectic knowledge and background of students attending Dalhousie Medical School and the continuing advancement of medical education within the Maritime Provinces. Featured articles detail topics such as international travel, artistic writing, the expansion of Dalhousie Medical School into the province of New Brunswick, and research, among others. The focus of this issue, however, is the theme of research. Numerous abstracts from students that have performed research projects in collaboration with multiple departments and divisions within the medical school are a testament of Dalhousie medical student's strong research efforts. Many of these abstracts will be presented at conferences worldwide and will receive awards of excellence or publication within peerreviewed journals.

One very important goal of the DMJ has been to support and publish the work of medical, graduate, and health professions students. Many authors will support the notion that journals listed within PubMed of the National Library of Medicine (NLM) will receive more submissions due to the greater impact that PubMed listed journals generally have. Also, some authors feel that literature listed within PubMed advances their career more through wider dissemination of research findings. Given the excellence of research at Dalhousie, we at the DMJ decided to begin an application for our school journal to be listed within PubMed. To do this, we have formed a Scientific Review Board that will ensure complete scientific validity of studies. We have also standardized our articles more so to ensure a uniform style for each type of article, whether it be a research-type or news-type paper.

We hope that within a year we will be able to say that our journal is one of the only medical school journals listed within PubMed in Canada. This, in turn, will highlight the research done by authors at Dalhousie University Medical School even more so and will increase the readership of the journal and dissemination of author's results. This will mark a pivotal step forward for medical student research at Dalhousie University and increase recognition of studentpublished articles across the nation. I am glad to have started this initiative during my last year as Editor so that the new DMJ team can focus upon making this idea become a reality.

Derek Roberts

Senior Editor-in-Chief, DMJ 